St. Christopher's Hospital for Children

Philadelphia, Pa.

REFERENCES

1 Strauss $A A$, Modanlou. Transient plasma cholinesterase deficiency in preterm infants. Dev Pharmacol Ther 1986; 9 82-7.

2 Zsigmond EK, Downs JR. Plasma cholinesterase activity in newborns and infants. Can Anaesth Soc J 1971; 18: 278-85.

3 Pasquariello $C A$, Schwartz RE. Plasma cholinesterase deficiency in a neonate. Can J Anaesth 1993; 40: 529-31.

\section{Drug labels on anaesthesia carts}

To the Editor:

In the January edition of the Journal, Drs. Boldt and Renwick ${ }^{1}$ stated that they had identified a safety hazard associated with 1 millilitre glass vials produced by Sabex Inc. The problem which they have identified occurs not only with Sabex.

We agree that medication error is an important cause of patient morbidity, and that to eliminate medication error there can be no substitute for reading a label. It is, however, the responsibility of hospital pharmacies and departments of anaesthesia to take special precautions to assure that medications with similar labeling are not placed in anaesthetic carts. Institutions and governments now frequently choose to purchase pharmaceuticals from the manufacturer who can supply product at the best price. Anaesthetists and pharmacists must take a proactive role in assuring that ampoules of similar colour and labeling are not placed side by side. In our hospital, we have a cooperative arrangement between the Department of Anaesthesia and the Pharmacy, assuring that changes in product are not introduced to the operating room without prior consultation. We have agreed that we will not place ampoules of similar size and colour on our anaesthetic carts where possible; to that end, we have occasionally requested a change in supplier simply to modify the size and colour of an ampoule. We have also occasionally requested a change in product concentration (e.g., atropine $0.4 \mathrm{mg} \cdot \mathrm{ml}^{-1}$ instead of atropine 0.6 $\mathrm{mg} \cdot \mathrm{ml}^{-1}$ ) specifically to obtain a different colour of ampoule. Where we previously had ampoules of atropine, adrenaline, and heparin all of the same size and colour, they are now very different from one another.

In discussing the problem of labeling of ampoules with manufacturers, we have found them sympathetic to our objective of reducing medication error, but reluctant to change their labeling to meet the needs of individual institutions. Our experience with Sabex Inc., however, has been positive and we concur with Mrs. Levesque's response.

\author{
Gerald V. Goresky \\ Department of Anaesthesia \\ Donna Pipa \\ Pharmacy Department \\ Alberta Children's Hospital \\ 1820 Richmond Rd SW \\ Calgary, Alberta T2T 5C7
}

\section{REFERENCE}

1 Renwick JE, Boldt $C$. Safety hazard - Sabex drug labels (Letter). Can J Anaesth 41: 1: 75-6.

\section{Anaesthesia for cardiac transplant patients}

To the Editor:

We read with interest the article of Cheng and Ong ${ }^{1}$ concerning anaesthesia for non-cardiac surgery in hearttransplanted patients. We would like to address the issue of the reported lack of effect of anticholinesterases on heart rate. The authors observed that "Paralysis was easily reversed with neostigmine with or without atropine. No significant effect on heart rate was recorded," and later claim that " ... heart rate shows no response to ... anticholinesterases (neostigmine, edrophonium, pyridostigmine, physostigmine) ... "While this view seems to be generally accepted ${ }^{2-4}$ we have demonstrated in cats that neostigmine can still evoke a marked, dose-dependent bradycardia when autonomic efferent activity to the heart is interrupted. The mechanism by which this occurs appears to involve direct activation by neostigmine of excitatory cholinergic receptors on cardiac ganglion cells, which results in release of acetylcholine from their terminals and subsequent activation of inhibitory cardiac receptors. ${ }^{5}$ We have also demonstrated that clinically relevant doses of neostigmine produce an atropine-sensitive bradycardia in both recently and remotely transplanted patients. ${ }^{6}$ We wish to draw attention to our observations that neostigmine can produce a clinically significant bradycardia in the heart transplant patient and we suggest that muscarinic antagonists be administered routinely with reversal agents to block cardiac and other muscarinic side effects of the anticholinesterases.
S.B. Backman MD PhD FRCPC
F.E. Ralley MB ChB
G.S. FoX MD FRCPC 
Department of Anaesthesia

Royal Victoria Hospital

McGill University

Montreal, Quebec.

\section{REFERENCES}

1 Cheng $D C H$, Ong $D D$ Anaesthesia for non-cardiac surgery in heart-transplanted patients. Can J Anaesth 1993; 40: 981-6.

2 Kanter SF, Samuels SI. Anaesthesia for major operations on patients who have transplanted hearts: a review of 29 cases. Anesthesiology 1977; 46: 65-88.

3 Eisenkraft JB, Dimich I, Sachdev VP. Anaesthesia for major non-cardiac surgery in a patient with a transplanted heart. Mt Sinai J Med 1981; 48: 116-20.

4 Grebenik $C R$, Robinson PN. Cardiac transplantation at Harefield. A review from the anaesthetist's standpoint. Anaesthesia 1985; 40: 131-40.

5 Backman SB, Bachoo M, Polosa $C$. Mechanisms of the bradycardia produced in the cat by the anticholinesterase neostigmine. J Pharm Exp Ther 1993; 265: 194-200.

6 Backman SB, Ralley FE, Fox GS. Neostigmine produces bradycardia in a heart transplant patient. Anesthesiology 1993; 78: 777-9.

\section{$R E P L Y$}

Thank you for the comments from Backman et al. on our article Anaesthesia for non-cardiac surgery in hearttransplanted patients ${ }^{\prime}$ concerning the reported lack of effect of anticholinesterase on heart rate. We reported in our series that 11 of the 12 patients who underwent general anaesthesia received intraoperative neuromuscular blocking agents (vecuronium $n=9$, pancuronium $n=2$ ). The fact is that no significant haemodynamic effect on heart rate was observed when the block in these patients was reversed with neostigmine with $(n=8)$ or without $(n=3)$ atropine. We later stated in our discussion that our result is consistent with the literature: it is generally accepted that heart rate shows no response to drugs like muscle relaxants, anticholinergics, anticholinesterases, etc. However, in the same paragraph, we did mention that slow development of cardiac reinnervation may be possible. ${ }^{2}$ I agree with the case report by Backman et al. ${ }^{3}$ that one of their heart transplanted patients had a decrease (21\%) in heart rate from 95 to 75 bpm after neostigmine administration. In the same report, they stated that two other previously heart-transplanted patients had a reduction of $7 \%$ and $14 \%$ in heart rate after neostigmine administration. However, we do not know if the decrease in heart rate is a consequence of cardiac reinnervation, prolonged denervation, or direct activation on cardiac ganglionic cells by anticholinesterases. ${ }^{4}$ I don't know if this can be justified as a clinically significant bradycardia as no decrease in blood pressure was reported simultaneously. As well, I consider a clinically significant bradycardia as a heart rate $<50$ bpm. I do not object that muscarinic antagonists be administered with anticholinesterases to block possible muscarinic side-effects of anticholinesterases in heart-transplanted patients. However, I will continue to utilize the heart transplant models for teaching residents regarding denervated heart physiology and pharmacology of anticholinesterase with or with anticholinergic agents.

\section{D.C.H. Cheng MD MSc FRCPC}

Department of Anaesthesia, The Toronto Hospital University of Toronto, Toronto, Ontario.

\section{REFERENCES}

1 Cheng DCH, Ong DD. Anaesthesia for non-cardiac surgery in heart-transplanted patients. Can J Anaesth 1993; 40: 981-6.

2 Wilson RF, Christensen BV, Olivari MT, Simon A, White $C W$, Laxson $D D$. Evidence for structural sympathetic reinnervation after orthotopic cardiac transplantation in humans. Circulation 1991; 83: 1210-20.

3 Backman SB, Ralley FE, Fox GS. Neostigmine produces bradycardia in a heart transplant patient. Anesthesiology 1993; 78: 777-9.

4 Backman SB, Bachoo M, Polosa C. Mechanism of the bradycardia produced in the cat by the anticholinesterase neostigmine. J. Pharm Exp Ther 1993; 265: 194-200.

\section{The oesophageal tracheal combitube for difficult intubation}

To the Editor:

We read with interest the report by Baraka and Salem describing the successful use of an oesophageal tracheal combitube (OTC) following a failed intubation in a patient with a potentially full stomach. ${ }^{1}$ As direct laryngoscopy revealed only a Cormack and Lehane grade 4 view, an OTC was inserted and the operation completed using controlled ventilation and a succinylcholine infusion. There are a number of points we would like to make about the use of the combitube in this situation.

Firstly, the authors did not state if facemask (FM) ventilation was attempted. In the "cannot intubate, cannot ventilate" situation, use of the OTC may be appropriate. ${ }^{2}$ If, however, adequate ventilation can be achieved with an FM and maintained cricoid pressure, use of the OTC could not be recommended since it is a blind technique and ideal placement is not guaranteed. In this circumstance, the most appropriate course of action is probably to wake up the patient and secure the airway using an awake technique before proceeding with surgery. If difficult tracheal intubation is anticipated, as in this case, we consider than an elective awake intubation technique would be wiser than a rapid sequence induction of anaesthesia where applied cricoid pressure may worsen the view of the larynx. ${ }^{3}$

Secondly, the authors comment that the OTC may be preferred to the laryngeal mask airway (LMA) in the difficult intubation situation whenever the patient is con- 